the given conditions was 13 of a foot ( $1 \frac{1}{2}$ inches only [!]), but even that is more than has been allowed in the design of this ship (viz. '12) in which the Committee say "a just balance " has been preserved. ${ }^{1}$ And this inability of the ship to withstand her own rudder's action, and that at a low speed, even with virgin armour and a bottom untouched by ram or torpedo, having been asserted and urged by others, elicits no remonstrance or objection whatever from the Committee. And yet, when a little later on in their Report they have disclosed a somewhat similar degree of longitudinal instability-discovered, as they suppose by themselves, but already well-known and obvious, doubtless, to others-and have shown that the ship would not be safe at seven and nine knots speeds because of her tendency to capsize lengthwise (so to speak), and so more or less down headforemost, then the Committee see grave danger showing itself, for they say, "We consider that any large limitation in the ship's speed may expose her dangerously to the attack of ram or torpedo," and in the summary they incidentally tell us, in the mildest terms, that a blow from either would be fatal; "the small residuum of stability she would possess would not avail to render such an attack other than fatal," The only clifference in the two cases is (and this is possibly the reason why the Committee lay the greater stress on this case) that it is not here necessary to suppose the cork or stores biown out, for a single shot or shell making a large wound near the stem, bulging a skin plate outwards, and completely rupturing the internal bulkheads, would so destroy the longitudinal stability of this large ironclad, costing more than half-a-million sterling, that even at seven knots' speed she would run her bows under; "and again," we a re told by the Committee, "her speed is similarly limited to nine knots by wounds of a much less critical character in other parts of her sides." "We have said that even this danger was doubtless foreseen by others-as it certainly was by ourselves, whether mentioned or not-before the Committee's Report appeared; but the Committee certainly have carried the subject a step forward by the experiments they have made with the model, and by their positive declaration that "on the whole the effect of sea-waves must be to aggravate, and in some circumstances greatly to aggravate," this very serious and certain source of danger. In a word, the very Committee who have in another place asserted that in the Inflexible the balance is fairly maintained between the armoured and unarmoured ends, have elsewhere in their Report shown that that balance is so ill maintained between the two, that with all the cork in place one or two shot and shell penetrating the unarmoured parts would so reduce her stability that she could not be steamed ahead with any reasonable speed, but would of necessity become a prey to any ram or torpedo craft that might evade or disregard her guns !

Another disclosure of the Committee is that the mere running out of the guns "would become a serious element of danger as the ship approaches the riddled and gutted condition." Here again they employ the phrase to which we have already intimated an objection in a foot-note, and speak of "the ship" approaching "the riddled and

${ }^{2}$ The Committee, at the bottom of page 15 , give us the means of readily illustrating the amount of stability which the Inflexible has lin the cas above considered, for they tell us that 60 tons in the bottom of the ship, which herself weighs over $I r, 000$ tons, would alter the length of $G Z$ to ' 12 of a foot. gutted condition." They mean nothing of the kind; by "the ship" they mean the exposed unarmoured ends only; and here again it is to be observed that the danger disclosed is not one contingent upon the blowing out of all the cork, \&c., but arises before, when the unarmoured part only approaches that condition. That the danger is, again in this case as in the previous one, a very serious and practical one is shown by the Committee recommending an alteration in the gunnery arrangements, proposing that the travel of the gun on the slides should be restricted, lest by running the guns out to the full extent at present arranged for, they should capsize the ship.

We have now sketched, sufficiently for our present purpose, the substance of the Committee's Report. We may end this article as we ended that of July 19 , and repeat: "The conclusions we have arrived at are, that the Inflexible is not a safe ship for battle in her present state, that the objections brought against her have been much too lightly treated, and that the disclosure of her condition, with the circumstances that have followed it, have excited just surprise and dissatisfaction." That surprise and dissatisfaction will be greater than ever when the Committee's Report has had time to produce its full effects, both intended and unintended.

\section{HYDROPHOBIA ?}

II.

JE do not intend to do more than allude in a cursory manner to the prophylactic treatment of hydrophobia, i.e. to the treatment adopted to prevent the occurrence of the disease in those who have been bitten by mad dogs. The general experience of the past sanctions, as might be expected, the practice of attempting to prevent the absorption of the poison of rabies by excising or destroying by caustics the wounds inflicted by rabid animals; of the innumerable internal remedies which have been proposed and made use of with the object of preventing the development of hydrophobia in those bitten by rabid dogs, it may be said with justice that nothing whatever is known which warrants the assertions of their advocates. This is indeed a case in which the fallacies which beset all therapeutical inquiries, especially when attempted by ignorant persons and fanatics, are specially liable to obscure the truth. Of all dogs supposed to be rabid, only an infinitesimal proportion really are so, and it is but rarely that the fact of a dog being rabid is tested by having it watched until it dies, or by the unfortunate fact that some of those bitten perish by hydrophobia ; then, of all persons bitten by certainly rabid dogs, only a small proportion become affected with hydrophobia, even when no treatment is adopted, so that the value of any drug or remedial measure as a prophylactic could only be tested by an experience such as no one ever has had.

Less uncertainty prevails in reference to the effects of treatment when hydrophobia has been developed. According to the best observers this disease has hitherto been invariably fatal. There are, it is true, a few casesand of these two have been recorded within a comparatively recent period-in which a cure is said to have been effected, but when examined with care the "gravest doubts

\footnotetext{
I Continued from p. Irg.
} 
of their real nature must be entertained. Here again there are fallacies to be encountered of no insignificant nature. The continued and terrible anxiety lest a bite which has been inflicted should be followed by its terrible consequences has led, in the case of persons of a susceptible and unstable nervous system-as all other long-continued worries and anxieties are liable to do-to the development of hysteria and insanity and, in the attacks of acute mania which have occurred in such individuals, many of the phenomena of hydrophobia have been imitated. An admirably-narrated case of this "hydrophobie non rabique" of French writers was lately placed on record by $\mathrm{Mr}$. Hugh Norris, of South Petherton ("Hydrophobia or its Eikon-which?"-Lancet, September 22, 1877):- "A gentleman underwent terrible anxiety on account of his young son having been bitten by a dog which suddenly had become ill and strange in its behaviour. The danger which threatened the boy caused the father to become intensely emotional, and prolonged sleeplessness ensued. Other worries superadded themselves to this one great gnawing anxiety, and the poor man fell ill; at first there appeared symptoms which simulated very closely the bydrophobic phenomena, but these were succeeded by a genuine attack of acute mania, which necessitated the patient's removal to an asylum, where he died on the seventh day of his illness." In this case there was no evidence that the patient was actually bitten by a dog, his statement that he had been so injared having been made, in a peculiarly suspicious manner, only after his illness had commenced, and being apparently but one of the delusions which afterwards haunted him. Had this man been certainly bitten, and had his illness been followed, as it might have been, by recovery, his case would in all probability have been quoted as one of the few instances of recovery from hydrophobia, though the impartial critic would have pointed out some anomalies which rendered the conclusion doubtful. The knowledge of the undoubted occurrence of such cases necessarily imposes great caution in the examination of alleged instances of recovery from hydrophobia.

The drug to which attention has of late been directed for the treatment of hydrophobia is curare or woorara, a substance used by the natives of South America as an arrow poison. This poison has been known since the end of the sixteenth century, when Sir Walter Raleigh made the conquest of Guinea ; but attention was drawn to it in a special manner by the celebrated traveller, Waterton, who first made experiments on animals with it, which were con inued by Sir Benjamin Brodie and Dr. Sibson, and were succeeded by the now celebrated researches of Claude Bernard, Kölliker, and other eminent physiologists. Curare, the active principle of which is derived from a strychniaceous plant, when directly introduced into the blood or injected under the skin, produces paralysis of all voluntary movements; this paralysis depends upon its exerting a special action upon the terminations of motor nerves in the muscles, especially in voluntary muscles. The poison leaves intact the sensory nerves of the body, and at least in the early stages of its action, the nervecentres. An animal subjected to its influence becomes absolutely motionless, and dies rapidly of suffocation from paralysis of the respiratory muscles ; if, however, respiration be kept up by artificial means, life may be prolonged for long periods, and, the poison becoming eliminated, recovery may ensue. As long, however, as the stage of complete paralysis continues, the creature is entirely unable to communicate with the external world. There is no proof that external stimuli do not affect it that it does not feel--but the channels by which the evidence of sensibility reach us are for the time interrupted. Curare has been suggested as a remedy for many diseases of a spasmodic character, but a great obstacle to its use is presented by the danger which attends its emiployment. A dose which will be sufficient to arrest an abnormal spasmodic contraction of a muscle or group of muscles, will presumably cause a stoppage of respiratory movemerits, and the medical man, if haply he be near the patient, will find himself compelled to keep up artificial respiration-no easy task to accomplish, especially with the means which the physician, as distinguished from the physiologist, could employ. Hitherto the attempts to use curare have been few, and the results (if we except the two supposed cases of cure of hydrophobia) we think worthless. Curare is indeed a drug the employment of which must be attended with so great a risk that a very strong case should be made out in its favour before patients are exposed to it.

Knowing as we do the physiological action of curare, we may ask whether it is a drug at all likely to be serviceable in spasmedic affections generally, and specially in hydrophobia. The majority of spasmodic diseases are due to a central cause, or to a cause acting through a preternaturally excitable centre. Any drug which will cut off-as curare does-the communication between the nerve-centre and the muscle will prevent its spasm, and will of course obviate any evil results which follow directly from the spasm; but, necessarily, under these circumstances the abolition of the spasm is no index that any change has been effected in the morbid state to which it owed its existence. In hydrophobia there occur, it is true, as prominent phenomena, spasms of the muscles concerned in inspiration and in deglutition. The administration of curare in doses sufficient to stop the respiratory movements would doubtless prevent these spasms, though we must not forget that it would do so at no mean risk. But are these spasms the proximate or remote cause of death in hydrophobia? We believe not. They are spasms which, as we tried to show, are probably dependent upon a morbid state of the medulla oblongata, with which is connected a morbidly heightened reflex excitability of that portion of the nervous system. But there is no evidence that curare would exert any influence in diminishing this abnormal excitability.

From our knowledge of the physiological action of curare we should not then be inclined to believe that it could affect in a beneficial manner the progress of the essential morbid processes of hydrophobia ; it could but modify some of the painful phenomena which belong to it. Actually curare has been tried in several cases, but only twice has its administration said to have been attended with success, and these two cases cannot be accepted as having been certainly cases of hydrophobia. We have seen one case of hydrophobia treated with curare without any influence having been exercised by it. There are drugs, however, which the physician is habitu- 
ally cmploying that possess actions which would cause one to predict that they would be of special use in controlling the terrible spasms of hydrophobia, e.g., bromide of potassium, chloral, and Calabar bean. These drugs all diminish in a signal manner the reflex excitability of the nerve-centres; and the second in the list possesses in addition powerful properties as a hypnotic; they have all been used in the treatment of hydrophobia ; and one of them-chloral-has, in sufficiently large doses, been successfully used, in so far as relief of suffering was concerned. But as for a cure for hydrophobia it has yet to be discovered; and this remark applies to all zymotic diseases. The majority of these diseases, unlike hydrophobia, tend naturally towards recovery rather than death, and the physician is undoubtedly able, by judicious measures, to obviate the tendency to death. He cannot cure the disease, however, in the sense in which he might be said to cure it were he able to destroy the poison which is its cause ; apparently, once introduced into the system the poison must produce its effects-intense or slightwhich must have a certain course, and then cease, because the poison which induced them has passed away, or because the soil which nourished the poison supplies it no longer with the conditions which it required. But the day may come, and we believe will come, when even this great result may be achieved; when not only shall we know the conditions which attend the spread of zymotic diseases so accurately that we shall be able to prevent their spread, but when medicine may supply us the means of dealing directly with the materies morbi of the diseases, as, for instance, by "sterilising" the soil in which they are irnplanted.

Our general review of the main facts in the history of rabies and hydrophobia has naturally brought out with considerable clearness how little is known concerning it, and how much remains to be done. We hail, therefore, with satisfaction the appointment of a Committee of the British Medical Association charged with the investigation of this important and interesting subject. This Committee consists of Dr. Lauder Brunton, Mr. Callender, Mr. Ernest Hart, and Prof. Burdon-Sanderson.

Before concluding, a few words concerning the measures to be adopted for preventing the spread of hydrophobia.

From our insular position we are in a better position than any neighbouring nation for holding a check, or even "stamping out" such a disease as hydrophobia, which, as the vast mass of evidence tends to show, does not originate spontaneously, nor does it appear that it would be difficult to effect this result were the suggestions which have been made by several recent writers carried into effect. It is certain that the number of dogs kept in England is enormously in excess of any requirements, and it is equally certain that this state of matters might promptly be put a stop to. The existing dog tax need not be increased in amount, but it should be enforced in the most stringent manner, the business of collecting, prosecuting, \&c., being handed over to the police authorities of each district. Each dog should have a separate number on the local register, and might be the wearer of a collar bearing its registered number. Further, the licence should bear a description of the premonitory symptoms of rabies, and owners of dogs should be cautioned in stantly to report any suspicious case to the police. These regulations would, as a necessary result, lead to each dog being individually looked after and cared for, and would, we believe, in the course of very few years, lead to the disappearance of rabies.

\section{DIEN'S "CELESTIAL ATLAS"}

Atlas Céleste, compronant toutes les Cartes de l'ancien Atlas de Ch. Dien. Rectifié, augmenté, \&c., par Camille Flammarion. $3^{\mathrm{e}}$ édition. (Paris : Gautbier-Villars, 1877.) THIS is a new and enlarged edition of Dien's "Atlas 1 Céleste," which first appeared in 1864, with the co-operation of M. Babinet, and is brought out under the editorship of M. Camille Flammarion. That the formation of the atlas, both in its original and extended plan has involved a great amount of labour will be evident upon a very superficial examination. The first issue was said to contain upwards of 100,000 stars and nebulæe, of which 50,000 had been observed by Lalande, projected on the development of a sphere, sixty-five centimètres in diameter, their places being reduced to the year 1860 , and this scale was stated to be sufficiently large to allow of the insertion without confusion of all stars to the ninth magnitude inclusive. The charts were said to contain " nearly the totality of stars in the catalogues of Lalande, Herschel I., Piazzi, Harding, Struve, Bessel, Herschel II., Groombridge, and Argelander," while for the southern heavens recourse was had to the catalogues of $\mathrm{La}$ Caille and Brisbane. This description of the authorities con. sulted is not very definite. The reference to Harding must apply to his atlas ; that to Bessel may be supposed to at least include the catalogue of equatorial stars observed by the Königsberg astronomer, which was prepared by Weisse of Cracow, and published in 1846 , if not the second catalogue founded upon Bessel's observations, containing stars from $15^{\circ} \mathrm{N}$. to $45^{\circ} \mathrm{N}$. declination, also reduced by Weisse, which appeared in 1863 . The reference to Argelander is especially indefinite ; we have the well-known catalogue of 560 stars, and the "Uranometria Nova," but previous to the year 1864, when "Dien's Atlas" was published, astronomers were also in possession of vols. 3, 4, and 5 of the "Durchmusterung," with the results of the survey of the whole northern heavens.

The programme originally prepared was a very exten. sive one. The new edition is stated to have received numerous corrections and considerable enlargement to bring up the work to the actual state of astronomical science, and there is sufficient evidence that an attempt has been made in this direction, but we regret to have to express the opinion, after a close examination of the "Atlas," that in its present state it does not fulfil the programme upon which it was formed. It will soon be evident, on comparing the maps with the charts issued by the Berlin Academy, or more generally with those in the original edition of Harding's Atlas, that so far from containing stars to the ninth magnitude inclusive, numerous eighths, and even stars of 6.7 magnitude, are omitted, and it is not easy to see from what cause. It might be inferred that Bessel's catalogue of equatorial stars had not been utilised, since stars of the seventh and eighth magnitude observed by Bessel and not observed by Lalande, are wanting. But in addition we soon miss stars that do occur in the "Histoire Céleste," as for 